\title{
The long-term success of coastal eco-city projects: studying examples from the EU and Asia
}

\author{
V. Kapnopoulou ${ }^{1}$, P. Divakaran ${ }^{2}$, E. McMurtry ${ }^{3}$, \\ M. Seo ${ }^{4} \&$ L. $\mathrm{Yu}^{5}$ \\ ${ }^{1}$ National Technical University of Athens, Greece \\ ${ }^{2}$ Australian Bureau of Meteorology, Australia \\ ${ }^{3}$ University of Southampton, UK \\ ${ }^{4}$ Seoul National University, South Korea \\ ${ }^{5}$ Shanghai Jiao Tong University, China
}

\begin{abstract}
Any coastal eco-city project can be executed perfectly. However, its long-term success relies heavily on the attitude of its stakeholders. This specific key factor is studied through the legal aspects of two juxtaposed coastal eco-city projects. Projects examined here are the "Helsingborg eco-city" from Sweden and the "Sino Singapore Tianjin eco-city" from China. These two case studies utilized different forms of contracts, agreements and legal practices. The structure of this research is of the essence as it indicates the progress of the project as well as its results. The research methodology includes comparative studies of both projects, on various legal aspects such as framework of the procuring process, type of procurement, decision making process, stakeholder engagement and contractual arrangements. This is followed by a survey and analysis of the benefits that accrue from the above choices, in order to identify optimized pathways to maximize the long-term success of the project. The study also identifies barriers in the project development and recommendations are made to policy makers and developers for future ecocity projects. Furthermore, transferability of the merits of each project regarding its legal aspects is examined for projects within its region and across EU-Asia borders.

Keywords: stakeholder management, contract type, eco-cities.
\end{abstract}




\section{Introduction}

Eco-city is a loosely defined term, and has often been used interchangeably with names such as sustainable city or smart city [1]. However, the World Eco-city Summit held in San Francisco in 2008, declared "An eco-city is an ecologically healthy city. Into the deep future, the cities in which we live must enable people to thrive in harmony with nature and achieve sustainable development. People oriented, eco-city development requires the comprehensive understanding of complex interactions between environmental, economic, political and sociocultural factors based on ecological principles. Cities, towns and villages should be designed to enhance the health and quality of life of their inhabitants and maintain the ecosystems on which they depend" [2]. San Francisco declaration also states that "eco-city development integrates vision, citizen initiative, public administration, ecologically efficient industry, people's needs and aspirations, harmonious culture, and landscapes where nature, agriculture and the built environment are functionally integrated in a healthy way" [2].

Similar definition of eco-cities can be found in the World Bank report on ecocities. "Ecological cities enhance the well-being of citizens and society through integrated urban planning and management that harness the benefits of ecological systems and protect and nurture these assets for future generations" [3]. Eco-cities can also be defined as Economical-Cities. "Economic cities create value and opportunities for citizens, businesses, and society by efficiently using the tangible and intangible assets of cities and enabling productive, inclusive, and sustainable economic activity" [3]. Hence, an eco-city brings together environmental, social and economic factors, along with comprehensive urban planning and management, for the long-term sustainability of human society.

The value of sharing experiences between EU and Asia is not an unknown concept; "EU-Asia Dialogue; Shaping a Common Future for Europe and Asia" [4] is the most prominent example applicable particularly to eco-cities. Predominantly, discussions revolved around practices in planning and performance of eco-cities globally, however, some emphasis was given to national practices, policy choices, obstacles, challenges and prospects. The main theme of the discussion pointed towards a mutual goal in gaining the strengths from one to another, mentioned was the dynamism of Asia, and the high standard of living in Europe being a quality the other desires to develop.

There is an undeniable disparity between the approaches taken by EU and Asian developers; however there are merits of both that may be of benefit to the other. Furthermore, the subject of eco-cities overlaps with innumerable other key issues of economic, social and environmental factors that need to be looked at as a whole. Asia is currently leading the global push towards developing eco-cities as it is the global leader in both city and eco-city developments. In Europe around $80 \%$ of the population live in small to medium sized towns and cities. In Asia, predominantly China and India, the sheer speed and scale of urbanisation has led to the development of huge population pressures on urban areas on an unprecedented scale [5]. Knowledge transfer between EU-Asia boundaries not only shares technical knowhow but can possibly help to overcome or at least start 
dialogue regarding a wider range of social, political and economic trans-national issues.

Technologies are widely shared around the world these days, and are managed by corporations of considerable wealth. However, there still exists notable difference in legal procedures in the government level between EU and Asia, which can affect the contractual procedures of a project. Disparities in cultures usually determine the fate of certain mode developments, as exemplified by Hald [6]. He noted that the Western ideals of development may not be applicable directly to Asian developments, as they have limited perspective on the history of Asian development in context, especially the Chinese civilisation. These peculiarities can be linked to contractual arrangement and stakeholder engagement, a key determining factor in the success of an eco-city project. Two cities from EU and Asia were selected for the case study. The one from EU is Helsingborg of Sweden, supported by the CONCERTO Initiative launched by the EU. The Asian city is Tianjin eco-city of China. The Tianjin eco-city is established as a flagship project for the cooperation between the governments of China and Singapore.

\section{Contract arrangement}

\subsection{The case of Helsingborg eco-city}

The joint development of eco cities in Scandinavia and Spain was part of the programme: "Sustainable Development, Global Change and Ecosystems: thematic priority 6 under the Focusing and Integrating Community Research Programme 2002-2006" by CORDIS [7].

To all participants in the 6th Framework Programme a consortium agreement (CA) was made among the parties, as it was defined by the rules adopted by the European Parliament and the Council for the participation of undertakings and for the dissemination of the research results (known as the Rules of Participation, or the "Rules"). A consortium agreement was an imperative factor for all projects financed by the 6th Framework Programme, except it was declared otherwise in the calls for proposals [8].

The contract types used for the projects under the 6th Framework Programme were [7]:

$>$ Networks of Excellence.

$>$ Integrated Project.

$>$ Specific Targeted Research Project.

$>$ Specific Targeted Innovation Project.

$>$ Coordination Action.

$>$ Specific Support Action.

For the project of the joint development of eco cities in Scandinavia and Spain, the contract type of "Integrated Project" was implemented [9]. 


\subsubsection{Integrated Project (IP)}

Integrated Projects are projects with multi-partners which are formed to support objective driven research, where the priority is to generate knowledge required to implement the thematic priorities. The IPs bring forth a large amount of critical resources in order to achieve ambitious goals to upgrade Europe's competitiveness or cope with major social issues. It is imperative to contain a research element and they may also involve technological development, demonstration components and perhaps a training element. The factor that differentiates the integrated projects is that of the "integration" that may take several forms within a project [10]:

$>$ Vertical integration of the whole "value-chain" of stakeholders reaching from those implicated in the knowledge production towards those involved in technological development and transfer.

$>$ Horizontal integration of several multidisciplinary activities.

$>$ Activity integration through incorporating various research activities from fundamental to applied research in combination with different types of activities such as take-up activities, protection and dissemination of knowledge, training, etc., as appropriate.

$>$ Sectoral integration of participants from private and public sector organisations, particularly academia and industry, including small medium enterprises (SMEs).

> Financial integration of public and private funds along with the overall financial plans that can involve the European Investment Bank and cooperation with Eureka (organisation to raise competitiveness and technology in Europe) [10].

Integrated Projects are knowledge and research driven, therefore the efficient management of knowledge as well as its circulation and transfer is of the essence within every integrated project along with an analysis and assessment of the technologies developed and the factors related to their exploitation [10].

\subsection{The case of Sino-Singapore Tianjin eco-city}

The project was initiated by Premier Wen Jiabao (PRC) and Prime Minister Lee Hsien Loong (Singapore) signing the "Framework Agreement on the Development of an eco-city in the PRC". The city was developed to be a model for sustainable development [11].

The Framework Agreement dictates that PRC and Singapore Government will cooperate and share their experiences in formulating policies and programs to bring forth social harmony. They will collaborate in the areas of urban planning, environmental protection, resource conservation, recycling, ecological infrastructure development, use of renewable resources, reuse of wastewater, and sustainable development in the Sino-Singapore Tianjin eco-city. The supervision mechanism for the city was also agreed upon the Framework Agreement [11].

Along with the Framework Agreement, a Supplementary agreement was signed by Minister Mah Bow Tan (Singapore) and Minister Wang Guangtao (PRC), in order to incorporate and reinforce the joint development of the Sino-Singapore Tianjin eco-city in accordance with the Framework Agreement [11]. 


\subsubsection{Framework agreement}

Framework agreement falls into the category of Framework Arrangements along with Framework Contracts. Framework arrangements have gained popularity as they comprise a "smarter way" to purchase works or supplies than placing "oneoff" orders for repeated contracts, as by that way volume purchasing discounts are optimized and repetition on purchasing tasks is minimized, among other benefits [12].

In a framework arrangement it is of the essence to establish a pricing structure, without implying a fixed price. Instead, a mechanism is launched and applied for pricing particular requirements and tasks during the period of the framework. Furthermore, it is tangible to establish the scope and types of services/works that will need to be called-off. Call-offs are individual contracts under framework arrangements in which the contracting authorities in the public and utilities sector do not need to repeat the process again as long as the rules for establishing the framework agreement in the first place were correctly observed. The option for call off arrangements can vary according to individual circumstances and specifically in the number of suppliers involved [12].

In a framework agreement, each time a buyer uses the agreement, a separate contract is formed by paying the consideration for the order in question. The consideration can be a purely nominal sum, which in the case of a dispute, will be interpreted by the court as confirmation that the parties are happy to be bounded with. Basically, a framework agreement is an agreement between two parties for the supply of an unspecified amount of product/works for a specified time period [12].

The benefits of a Framework Agreement include the reduction of costs and delays associated with the procurement process and the possibility of generating economies of scale, particularly if it is to be used by many authorities. The risks involve the time frame of the Agreement which is normally limited to four years, in the case of multi-authority use the Agreement may not be tailored to the needs of the participants. Moreover, the scaling up may have adverse effects to Small Medium Enterprises [13].

\section{Stakeholder engagement}

\subsection{The case of Helsingborg eco-city}

It is paramount for the project's success to continuously interact with the different stakeholder groups so that they can accept the planned measures. The SE activities are targeted towards various stakeholders, such as residents, tenants or owners of the buildings redeveloped as well as their associations. Moreover, public and private housing associations and building developers are also aimed either by a range of stakeholder engagement measures or by involving those in the measures that address the tenants and residents [14]. Professionals were involved in the process sometime as a targeted group but sometimes as a collaborator. The group of professionals involves installers, energy consultants, building professionals, caretakers, sales agents and municipal employees. This group is targeted by training activities and information events [14, 15]. 
Groups in the education and academic level (schools, kindergartens, universities) were addressed by courses and lessons for pupils and students. Private companies especially the Small Medium Enterprises (SMEs) were either collaborating stakeholders e.g. on smart metering or campaigns to raise awareness or target groups for guidance on energy usage [15].

The socio-economic activities that took place in all the cities of the Concerto initiative included five different categories and were tailored based on the community that was implemented. For example, in Helsingborg there was no socio-economic plan, however there were activities concerning environmental education and raising awareness, hence the range of activities regarding the stakeholder engagement involved [15]:

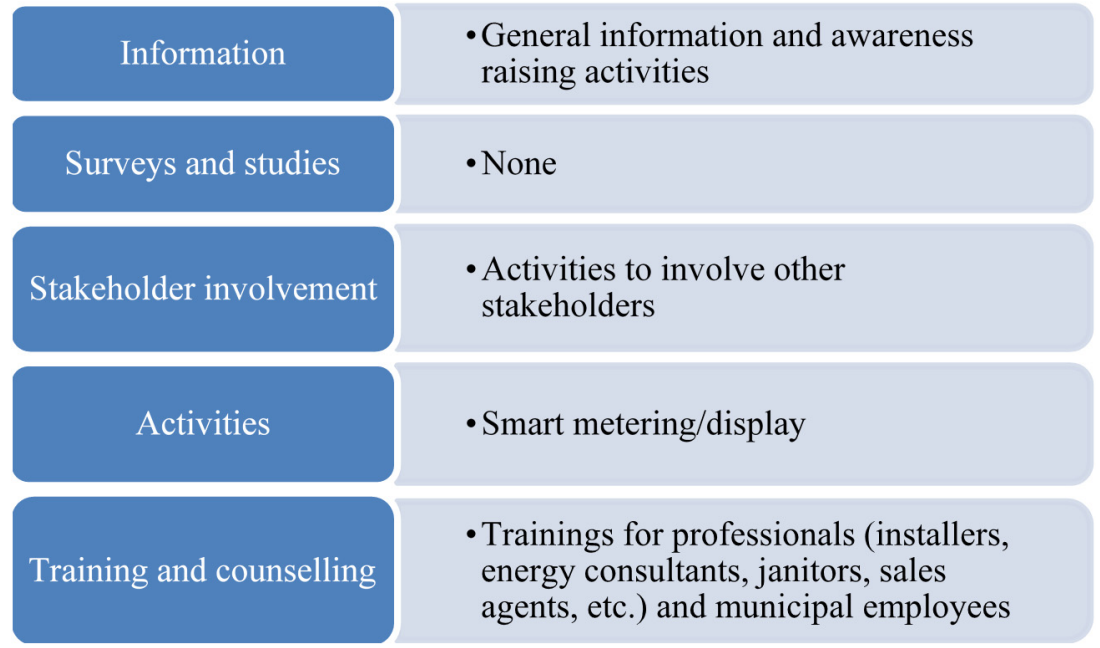

Figure 1: Activities for stakeholder engagement.

Involving the stakeholders in the process from the outset towards making a commitment, makes people more likely to act and reduces disputes [16]. Interpreting the groups implicated, inhabitants and home owners was one key to successful refurbishment activities. The key fact is the involvement of those affected by the measures so as to ascertain acceptability of the project and social response. It is crucial that participation of the people affected by the project is provided at every stage from planning through to implementation and is of the essence to keep them informed about the development $[14,15,17]$.

\subsection{The case of Sino-Singapore Tianjin eco-city}

In the case of Tianjin eco-city there were many different stakeholders involved; the Chinese and Singapore central government, local governments and municipalities, developers, architects, residents, organizations and companies. The variety of the stakeholders implicated can create a difficult situation as it is likely that each one of them will have different priorities in terms of sustainable 
urban development. Their differentiated interests can be proven highly problematic for the success of the project [16].

During the planning process a specific team (by Mott MacDonald company) was appointed by Sino Singapore Tianjin eco-city Administrative Committee and Global Environment Facility (GEF) to provide technical assistance but more important, to develop a strategy to educate and engage the stakeholders involved in order to encourage low energy living.

The team lead the design of two demonstration projects: a $20,000 \mathrm{~m}^{2}$ school and a 600 -apartment residential complex. They will both show a $65 \%$ saving in annual energy compared with the previous national standard benchmark. The team of Mott MacDonald Company worked with local design teams on the demonstration projects to shape the sustainable design features and improvements that can be employed, along with their relative cost, to define the final, costeffective designs [18].

\section{Comparison of the concept behind the contract arrangement}

The two case studies utilized different forms of contracts and agreements to materialize the projects. In Table 1 the aims and objectives of each contract type are depicted.

\subsection{Transferable best practices}

On one side there is the benefit of creating a research-driven project by establishing the contractual arrangement of an integrated project and on the other side there is the reduced bureaucracy which a Framework Agreement provides.

Apart from the clearly technical barriers, such as the formulation of a template and the legislative establishment of the contractual type, of the Framework Agreement or the Integrated Project respectively, other reasons are barriers to transferability as well.

Regarding the "bureaucracy" element, it is imperative to have pre-existing trust among the contracting members. The element of "trust" is of the essence especially in the case of Framework Agreements as the awards of "call-off" individual contracts do not occur within the process of procurement, therefore there should be mutual trust that the award of contract was made according to the perceptions and beliefs of all implicated parties. In the case of the project being conceived as a research/development opportunity or simply as a "purchase of goods", it lies completely in the perception of the contracting authorities.

\section{Conclusion}

As described above, the contractual concept and the way the developers decided to engage the stakeholder are highly differentiated. The merits of each process should be explored and as the projects are recently finished (Helsingborg) or unfinished yet (Tianjin eco-city), the literature should be exploited on that matter. 
Table 1: Comparison of the two contractual concepts.

\begin{tabular}{|c|c|}
\hline Framework Agreement (FA) & Integrated Project (IP) \\
\hline $\begin{array}{l}\text { It is a "smarter way" to purchase } \\
\text { works or supplies than placing "one- } \\
\text { off" orders for repeated contracts. }\end{array}$ & $\begin{array}{l}\text { Describe projects with multi-partners } \\
\text { which are formed to support objective } \\
\text { driven research, where the priority is to } \\
\text { generate knowledge. }\end{array}$ \\
\hline $\begin{array}{l}\text { The volume purchasing discounts are } \\
\text { optimized and repetition on purchasing } \\
\text { tasks is minimized. }\end{array}$ & $\begin{array}{l}\text { IPs bring forth a large amount of critical } \\
\text { resources in order to achieve ambitious } \\
\text { goals to upgrade Europe's } \\
\text { competitiveness or cope with major social } \\
\text { issues. }\end{array}$ \\
\hline $\begin{array}{l}\text { A mechanism is launched and applied } \\
\text { for pricing particular requirements } \\
\text { and tasks during the period of the } \\
\text { framework. }\end{array}$ & $\begin{array}{l}\text { It is imperative to contain a research } \\
\text { element that may also involve } \\
\text { technological development, } \\
\text { demonstration components and perhaps a } \\
\text { training element. }\end{array}$ \\
\hline $\begin{array}{l}\text { The scope and types of services/works } \\
\text { that will need to be called-off is } \\
\text { established at the outset. }\end{array}$ & $\begin{array}{l}\text { The fact that differentiates integrated } \\
\text { projects is diversity and different levels of } \\
\text { the "integration" within a project } \\
\text { (knowledge integration). }\end{array}$ \\
\hline $\begin{array}{l}\text { In individual contracts under } \\
\text { framework arrangements (call-offs) the } \\
\text { contracting authorities in the public } \\
\text { and utilities sector do not need to } \\
\text { repeat the procurement process again, } \\
\text { as long as the rules for establishing the } \\
\text { framework agreement in the first place } \\
\text { were correctly observed. }\end{array}$ & $\begin{array}{l}\text { It is of the essence to have a series of well } \\
\text { documented agreements upon the } \\
\text { administrative arrangements that will } \\
\text { efficiently tackle issues regarding the } \\
\text { project's aims and objectives, the } \\
\text { management of the project and the } \\
\text { allocation of resources and risks. }\end{array}$ \\
\hline $\begin{array}{l}\text { Basically, a framework agreement is an } \\
\text { agreement between two parties for the } \\
\text { supply of an unspecified amount of } \\
\text { product/works for a specified time } \\
\text { period. }\end{array}$ & $\begin{array}{l}\text { Efficient management of knowledge as } \\
\text { well as its circulation and transfer is of } \\
\text { the essence of every IP. }\end{array}$ \\
\hline
\end{tabular}

Contemporary literature considers the group of stakeholders as paramount to the success of sustainable projects therefore targeted projects are launched to identify proper ways to manage them so as to ascertain positive effects of them to the projects [19]. Stakeholder engagement process has been found to be an investment to sustainable projects as the implementation of a structured process to involve the stakeholder groups can support the trust to the developers of the projects $[19,20]$. Considering that, the employment of a contract type which promotes research and innovation in several fields, for example that of an Integrated Project, is profoundly preferable when the aim is to achieve a long-term success of a sustainable project. 


\section{References}

[1] Alusi, A., Eccles, R. G., Edmondson, A. C. and Zuzul, T., 2011. Sustainable Cities: Oxymoron or the Shape of the Future? Harvard Business School Working Paper, 11-062.

[2] San Francisco Eco-City Declaration, 2008. Eco-City Media (blog), May 15, 2008 (9:13pm), retrieved from: http://ecocity.wordpress.com/2008/05/15/ san-franciscoecocity-declaration

[3] Suzuki, H., Dastur, A., Moffatt, S., Yabuki, N. and Maruyama, H., 2010. Eco2 Cities: Ecological Cities as Economic Cities, The World Bank, ISBN 978-0-8213-8046-8.

[4] European Union, 2012a. EU-Asia Dialogue - Shaping a Common Future for Europe and Asia, Conference Report, Eco-Cities - Sharing European and Asian Experiences in Sustainable Urban Management, Singapore, May 25th 2012.

[5] Fook, L. L. and Gang, C., 2010. Towards a liveable and sustainable urban environment: Eco-Cities in East Asia, World Scientific Publishing, Singapore.

[6] Hald, M., 2009, Sustainable Urban Development and the Chinese Eco City: Concepts, Strategies, Policies, Assessments, retrieved from: http://www.fni.no/doc\&pdf/FNIR0509.pdf., accessed on: 20 August 2013.

[7] Community Research and Development Information Service (CORDIS), 2013, "Programmes", http://cordis.europa.eu/fetch?CALLER=PROGLINK NEWS_EN\&ACTION=D\&DOC $=1 \& C A T=P R O G \& Q U E R Y=01408 \mathrm{~b} 99$ $\overline{4} \mathrm{f} 01: \mathrm{d} 6 \overline{41}: 22 \mathrm{df0} 0 \mathrm{ea} \& \mathrm{RCN}=715$

[8] Community Research and Development Information Service (CORDIS), 2003, "FP6 Consortium Agreement Checklist", http://cordis.europa.eu/ fp6/stepbystep/consortium_agreement.htm

[9] 2020-Horizon.com, 2011, "Joint Eco-city Development in Scandinavia and Spain (Eco-City)", http://www.2020-horizon.com/ECO-CITY-Joint-ECOCity-developments-in-Scandinavia-and-Spain(ECO-CITY)-s22683.html

[10] European Commission, 2002, "The Sixth Framework Programme in brief", http://ec.europa.eu/research/fp6/pdf/fp6-in-brief_en.pdf

[11] Singapore Government, 2012, Tianjin Eco-city; A model for Sustainable Development, http://www.tianjinecocity.gov.sg/col_overview.htm

[12] Chartered Institute of Purchasing and Supply (CIPS), 2013, "Framework Arrangements", http://www.cips.org/Documents/Resources/Knowledge \%20Summary/Framework\%20Arrangements.pdf

[13] Giffin Nigel, 2011, "Some Issues Concerning Framework Agreements", www.whitepaperdocuments.co.uk

[14] El-Gohary, Osman, El-Diraby, 2006, "Stakeholder management for Public Private Partnerships", International Journal of Project Management, Vol. 24, Issue 7, pp. 595-604.

[15] Di Nucci, M. R, and Spitzbart, C., 2010. Concerto: Socio-Economic Impact Assessment Report, http://www.polsoz.fu-berlin.de/polwiss/forschung/ 
systeme/ffu/publikationen/2010/di_nucci_socio_eco/concertoplus exsummary_se.pdf

[16] Mok, Shen, Yang, 2014, "Stakeholder management studies in mega construction projects: A review and future directions", International Journal of Project Management, In Press Corrected Proof.

[17] Missonier, Loufrani-Fedida, 2014, "Stakeholder analysis and engagement in projects: From stakeholder relational perspective to stakeholder relational ontology". International Journal of Project Management, Vol. 32, Issue 7, pp. 1108-1122.

[18] Mott MacDonald, 2013, Sustainability Tool, http://www.mottmac.com/ corporateresponsibility/sustainability/sustainabilitytools/

[19] Dvarioniene J., Gurauskiene I., Gecevicius G., Trummer D.R., Selada C., Marques I., Cosmi C., 2015, "Stakeholders involvement for energy conscious communities: The Energy Labs experience in 10 European communities", Renewable Energy, Vol. 75, pp. 521-518.

[20] Waligo V.M., Clarke J., Hawkins R., 2014, "The 'Leadership-Stakeholder involvement capacity' nexus in stakeholder management”, Journal of Business Research, Vol. 67, Issue 7, pp. 1342-1352. 